\title{
Arthropod community structure in pastures of an island archipelago (Azores): looking for local-regional species richness patterns at fine-scales
}

\author{
P.A.V. Borges ${ }^{1 *}$ and V.K. Brown ${ }^{2}$ \\ ${ }^{1}$ Department of Biology and NERC Centre for Population Biology, Ascot, \\ Berks, SL5 7PY, UK: ${ }^{2}$ Centre for Agri-Environmental Research, Department \\ of Agriculture, University of Reading, Earley Gate, PO Box 237, \\ Reading, RG6 6AR, UK
}

\begin{abstract}
The arthropod species richness of pastures in three Azorean islands was used to examine the relationship between local and regional species richness over two years. Two groups of arthropods, spiders and sucking insects, representing two functionally different but common groups of pasture invertebrates were investigated. The local-regional species richness relationship was assessed over relatively fine scales: quadrats (= local scale) and within pastures (= regional scale). Mean plot species richness was used as a measure of local species richness ( $=\alpha$ diversity) and regional species richness was estimated at the pasture level ( $=\gamma$ diversity) with the 'first-orderJackknife' estimator. Three related issues were addressed: (i) the role of estimated regional species richness and variables operating at the local scale (vegetation structure and diversity) in determining local species richness; (ii) quantification of the relative contributions of $\alpha$ and $\beta$ diversity to regional diversity using additive partitioning; and (iii) the occurrence of consistent patterns in different years by analysing independently between-year data. Species assemblages of spiders were saturated at the local scale (similar local species richness and increasing $\beta$-diversity in richer regions) and were more dependent on vegetational structure than regional species richness. Sucking insect herbivores, by contrast, exhibited a linear relationship between local and regional species richness, consistent with the proportional sampling model. The patterns were consistent between years. These results imply that for spiders local processes are important, with assemblages in a particular patch being constrained by habitat structure. In contrast, for sucking insects, local processes may be insignificant in structuring communities.
\end{abstract}

\section{Introduction}

Regional species richness (RSR) or the pool of available species is an important factor, known to influence local

*Present address and address for correspondence: Universidade dos Açores, Dep. de Ciências Agrárias, TerraChã, 9700-851 Angra do Heroísmo, Terceira, Açores, Portugal Fax: 00351295402205

E-mail: pborges@angra.uac.pt species richness (LSR) (e.g. Cornell, 1993; Ricklefs \& Schluter, 1993; Lawton, 1999; Gaston \& Blackburn, 2000). This differs from the idea that local species richness is solely determined by ecological processes operating at the local community scale, such as strong interactions between species, disturbance, limited niche space and limited dispersal capabilities (Caley \& Schluter, 1997).

Two models have been proposed to explain how local and regional species richness are related in natural communities (Cornell, 1985a,b; Ricklefs, 1987; Cornell \& Lawton, 1992; Srivastava, 1999): 
1. The proportional sampling model, in which local species richness (' $\alpha$-diversity') increases proportionately with regional species richness (type I model, fig. 1). In this model, local processes are of minor importance and regional processes such as historical and biogeographic constraints, as well as immigration and extinction events (e.g. random colonization and extinction), can shape the species richness of local communities.

2. The local saturation model, in which local species richness reaches a ceiling in richer regions. In this model, local processes (e.g. biotic interactions between species, abiotic characteristics of the habitat, disturbance) limit the number of species that can coexist in a local community. Thus, local species richness is largely independent of the pool of species occurring in the region (type II model, fig. 1).

Despite the available empirical and theoretical data, an examination of the literature reporting local-regional species richness patterns reveals a distressing lack of uniformity in the way local and regional richness are estimated and in the type of statistical procedures used. Methodological pitfalls are common (for a review see Srivastava, 1999) and several solutions to avoid pseudoreplication and how to chose the most appropriate model have been proposed (Griffiths, 1999; Srivastava, 1999).

Particularly striking is the almost complete absence of tests of the 'proportional sampling' or 'local saturation' models in different seasons of the year or between different years (but see Hugueny \& Paugy, 1995). In fact, taking into account that biotic interactions between species occur in space (local scale) and time (the length of the life cycle), lumping seasonal and annual data, as has been done by most authors, can carry risk. With some taxa (e.g. corals, perennial plants) this is probably unimportant, but for species with short lifespans (e.g. arthropods), if competition occurs, assessments should be made over shorter time scales. In order to test rigorously for the existence of saturation in natural arthropod communities, seasonal or between-year data should be analysed independently.

Another important methodological aspect relates to the scales at which regional and local species richness are quantified. Most empirical studies have investigated the

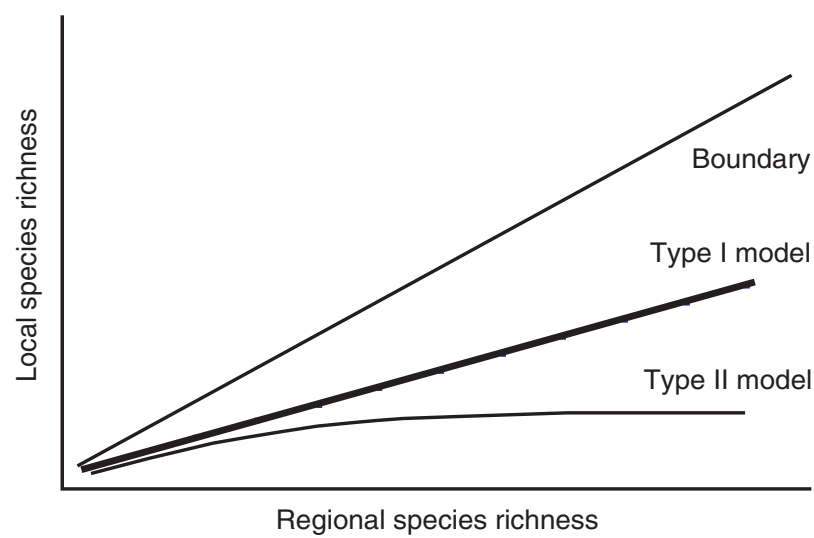

Fig. 1. Relationship between local species richness (LSR) and regional species richness (RSR): type I model - 'proportional sampling'; type II model - 'local saturation'. The boundary line represents a situation in which LSR equals RSR (slope $=1$ ) (redrawn from Cornell \& Lawton, 1992; Cornell, 1993).
LSR-RSR relationship over relatively broad geographical scales, where the 'proportional sampling model' has been found to be the primary explanation of local species richness (see Caley \& Schluter, 1997). Moreover, recent empirical and theoretical work suggests that plotting local-regional species richness relationships is counterproductive in testing the strength of interactions in communities (Fox et al., 2000; Loreau, 2000; Valone \& Hoffman, 2002), and recommends some emphasis should be given to testing the relationship between $\alpha$ (local) and $\beta$ components of diversity and to understand how the processes work at multiple scales (Loreau, 2000).

In this study, and similar to those of Winkler \& Kampichler (2000) and Soares et al. (2001), the LSR-RSR relationship is assessed over relatively fine scales: quadrats (= local scale) and within pastures (= regional scale). This paper aims to:

1. Assess whether variables other than regional species richness may explain local species richness. Hierarchical multiple regression is used to evaluate the relative importance of several local vegetation structure variables, regional species richness and geographical regional variables in determining local species richness. As biotic interactions between species are more likely to occur in assemblages of functionally similar species, eventually competing for a common resource, sucking insect herbivores and vegetation-dwelling spiders were chosen as study groups. Spiders may compete for resources (Wise, 1995), but also for space where they can build their webs (Brown, 1991a,b; Uetz, 1991). The absence of competing interactions between herbivorous arthropods is commonly reported (Strong et al., 1984; but see Denno et al., 1995 and Moon \& Stilling, 2002 for some new insights on competitive processes in herbivore insects). It is predicted that regional species richness should explain local species richness of herbivorous insects ('proportional sampling model'). On the other hand, because competition in predators is more likely to occur (Cornell \& Karlson, 1997), it is predicted that spiders are locally saturated ('local saturation model') either by competition or other local processes, and that vegetation structure variables should explain local species richness.

2. Quantify the relative contributions of $\alpha$ and $\beta$ diversity to regional diversity using additive partitioning.

3. Evaluate the importance of analysing independently between-year data in testing the above mentioned models looking for consistent patterns between years.

\section{Materials and methods Sites and experimental design}

This study was carried out in the Azores, an isolated northern Atlantic archipelago that comprises nine islands, as well as several islets and seamounts distributed from northwest to south-east, roughly between $37^{\circ}$ and $40^{\circ} \mathrm{N}$ and $24^{\circ}$ and $31^{\circ} \mathrm{W}$. Extending for about $615 \mathrm{~km}$, the Azorean islands are situated across the Mid-Atlantic Ridge, which separates the western group (Flores and Corvo) from the central (Faial, Pico, São Jorge, Terceira and Graciosa) and the eastern (São Miguel and Santa Maria) groups. All these islands are of volcanic origin and more than half of current Azorean land is pasture of some kind (Garcia \& Furtado, 1991; Martins, 1993). The climate is temperate oceanic, i.e. strongly influenced by the proximity of the ocean, which produces 
high levels of relative atmospheric humidity that can reach 95\% in high altitude native semi-tropical evergreen laurel forest, as well as restricting temperature fluctuations throughout the year.

A detailed description of the sites is presented elsewhere (Borges, 1997, 1999a,b; Borges \& Brown, 1999). Two $900 \mathrm{~m}^{2}$ replicates of upland, recently-sown pastures (3-4 years old) and upland wet semi-natural old pastures (more than 35 years old) were selected in three Azorean islands (Santa Maria, Terceira and Pico) totalling 12 sites ( 3 islands $\times 2$ habitats $\times 2$ replicates). To minimize effects other than those due to the factors under investigation, the selected pastures had continuity of management intensity for at least four years (sown pastures) and more than 15 years (semi-natural pastures). There was no consistent habitat effect on arthropod species richness but a clear island effect (Borges, 1999a; Borges \& Brown, 1999). Therefore, the 12 pastures were not independent regional samples and a hierarchical regression model was used (see data analysis). To manipulate and standardize the periods of cattle grazing, all 12 pastures were fenced during January and February 1994, with additional rabbit fences erected in April of the same year. Twenty $3 \times 3 \mathrm{~m}$ quadrats were demarcated, in each of the $900 \mathrm{~m}^{2}$ replicates. All the fenced sites were grazed regularly by dairy and beef cattle, thereby maintaining the traditional management of the sites. Grazing regime was random and grazing intensity was 10-20 cattle per site allowing complete grazing of the vegetation. Duration of grazing was inversely proportional to the number of animals introduced.

\section{Vegetation and arthropod sampling}

Sampling occurred at least three weeks after a grazing period, to allow regrowth of the vegetation. Vegetation and arthropod data were collected on several occasions, but for current purposes the summer samples for two consecutive years are analysed (1994 and 1995). The vegetation was sampled by point-quadrat and the arthropods by suction. In each of the 20 quadrats, two linear 10 pin frames (pin height $=1.10 \mathrm{~m}$ ) were placed at random. A total of 400 pointquadrat pins, were used for each field site on each sampling occasion. The number of touches of each living plant species was recorded at $2 \mathrm{~cm}$ (below $10 \mathrm{~cm}$ ) or $5 \mathrm{~cm}(10 \mathrm{~cm}$ and above) height intervals, to provide a measure of sward architecture (see Borges 1999a,b and Borges \& Brown, 1999, 2001 for details).

Invertebrate sampling was carried out between 11.00 and $18.00 \mathrm{~h}$ on warm, sunny days when the vegetation was dry. In each of the 20 quadrats in each field site, four random subsamples were taken, one in each corner of the $3 \times 3 \mathrm{~m}$ square quadrat (a total area of $0.8 \mathrm{~m}^{2}$ ). The collection nozzle was held in position for $30 \mathrm{~s}$ on each occasion. To speed up sampling (important in the changeable weather in the Azores) and simplify sorting, the four subsamples in a plot were pooled. The samples were stored in $70 \%$ ethanol with glycerol prior to sorting.

The arthropod assemblages studied comprised: sucking insects - all insect species reported to feed on grasses and forbs (Hemiptera, Thysanoptera); spiders - all species of web-building spiders (Tetragnathidae, Araneidae, Linyphiidae, Theridiidae and Dictynidae), plus three species of hunting spiders (Lycosidae: Pardosa acorensis Simon; Thomisidae: Xysticus cor Canestrini and Xysticus nubilis
Simon). Details of species identification are available in Borges \& Brown (1999) and the list of species is given in Borges (1999a).

\section{Vegetation structure variables}

Vegetation data were collated to give a range of potential explanatory measures (see also appendix II in Borges \& Brown, 2001 for data acquisition). Each measure was assessed for the summer sample for two consecutive years. Two measures are strictly descriptors of vegetation structure (cover abundance and height), whereas William's $\alpha$ diversity $(\mathrm{W}-\alpha)$ and several measures of vegetation species richness measured at quadrat (local) scale were also used as potential surrogates of local arthropod species richness. The plant diversity variables described below were also used as potential descriptors of vegetation structure since William's $\alpha$ diversity (W- $\alpha$ ) uses point-quadrat touch data and it is expected that the probability of additional plants having new structural characteristics suitable for spider-web attachment will increase in proportion to the number of plant species.

\section{Cover abundance (ca)}

This was calculated as the number of touches of a species on a set of 20 height-profile point-quadrat pins (20 quadrats $\times 20$ pins). This measure gives a reliable estimate of cover abundance (also referred to as cover) for a species and can be related to biomass (Brown et al., 1988). As most forb and grass species in the sites were perennial, the mean perennial forb cover abundance (PEFca) per quadrat and the mean perennial grass cover abundance (PEGca) per quadrat were selected as potential explanatory variables of quadrat arthropod richness.

\section{Height (ht)}

A measure of plant structure. The weighted mean height of the total vegetation (V-ht), the perennial forbs (PEF-ht) and the perennial grasses (PEG-ht) was calculated for each quadrat (20 pins) using the expression:

$$
\sum_{\mathrm{i}=1}^{\mathrm{N}}\left(\mathrm{h}_{\mathrm{i}} \times \mathrm{n}_{\mathrm{i}}\right) / \sum_{\mathrm{i}=1}^{\mathrm{N}}\left(\mathrm{n}_{\mathrm{i}}\right)
$$

where $\mathrm{h}=$ the midpoint of the height class $i, n_{i}=$ number of touches at height class $i$ and $\mathrm{N}=$ number of height classes represented in the sample (Gibson et al., 1987). Means were taken from 20 quadrats for each site.

\section{William's $\alpha$ diversity $(W-\alpha)$}

Plant diversity was measured using the Williams's $\alpha$ index $(\alpha)$ (see Southwood, 1978; Southwood \& Henderson, 2000):

$$
S=\alpha \ln (1+\mathrm{N} / \alpha)
$$

Plant structural diversity was assessed from the multiple touch data, using the above formula, where $\alpha$ is the $\alpha$ of the $\log$ series, $S$ is the summation of the number of species in each height class and $N$ the total of number of touches in the sample (see Brown \& Gange, 1989). This index (W- $\alpha$ ) was only calculated for the total vegetation in each plot. Means were taken from 20 quadrats for each site. 


\section{Species richness (Sprich)}

The mean number of vascular plant species touching the point-quadrat pins (Sprich) was used as a measure of plant species richness. This measure was calculated for all vascular plant species and means were estimated from 20 quadrats for each site. Clearly, species touching all pins are the most frequent species in the sites. In addition, two other measures of species richness were used: total forb species ('tFspp') and total grass species ('tGspp'). In both cases, species richness was obtained by pooling the 20 quadrats $(\gamma$ diversity).

\section{Local and regional species richness estimates}

Each pasture was considered as one region $(n=12)$, while each of the twenty 9- $\mathrm{m}^{2}$ quadrats, was considered a local area. A $9-m^{2}$ plot was small enough to permit all spiders and sucking insect species living in the square to interact potentially. Similar to the procedure of other workers (Tonn et al., 1990; Hawkins \& Compton, 1992; Valkenburgh \& Janis, 1993; Dawah et al., 1995), local species richness (LSR) $(=\alpha$-diversity) in each pasture was calculated as the mean number of species per quadrat using 20 quadrats. This is equivalent to Whittaker's point diversity (Whittaker, 1972; Whittaker et al., 2001).

Since not all species in the pasture (region) could be sampled, regional species richness (RSR) for each pasture was obtained using the 'first-order-Jackknife estimator' (Colwell \& Coddington, 1995; Colwell, 1997; Henderson \& Seaby, 1998):

$$
\mathrm{S}_{\max }=\mathrm{S}_{\text {obs. }}+\mathrm{a}(\mathrm{n}-1 / \mathrm{n})
$$

in which, $\mathrm{S}_{\text {obs. }}=$ pooled number of species actually sampled in the 20 quadrats, $n=$ number of samples (quadrats) $(\mathrm{n}=20)$ and $a=$ number of species only found in one sample (quadrat) (= uniques). Therefore, $\mathrm{S}_{\text {obs. }}$ is the same as $\gamma$-diversity sensu Whittaker (1972).

Curves obtained when estimating the 'first-orderJackknife' estimates were the average of 100 randomizations and were tested for heterogeneity using the Coleman test, that compares the mean randomized species accumulation curve with the curve expected if all the individuals caught over all the samples were randomly assigned to the samples
(Colwell \& Coddington, 1995). Based on that index, it was confirmed for all pastures that the species accumulation curve was derived from a homogeneous (stable) community, i.e. the expected curve did not rise more steeply from the origin than the accumulation curve, implying that heterogeneity was not greater than could be explained by random sampling error alone (Colwell \& Coddington, 1995). The computations were performed using the software Species Diversity and Richness version 2.3 (Pisces Conservation) (see Henderson \& Seaby, 1998). The 'firstorder-Jackknife' estimator also allows the maintenance of statistical independence between response (LSR) and explanatory (RSR) variables. This is because RSR is not obtained directly from the accumulating number of species in local quadrats (equivalent to $\gamma$-diversity), but includes a $\beta$ diversity component given by the species richness estimator (for similar procedures see Winkler \& Kampichler, 2000; Soares et al., 2001).

\section{Data analysis}

\section{LSR-RSR relationship: contributions of $a$ and $b$ diversities}

There is a recent movement to encourage authors to use the additive form of $\beta$-diversity in which $\gamma$-diversity $=\alpha+\beta$ (i.e., $\beta=\gamma-\alpha$ ) (see Loreau, 2000; Gering \& Crist, 2002; Veech et al., 2002), instead of the traditional Whittakers's multiplicative format. In this case, $\gamma$-diversity is the accumulated number of species in a pasture (region), not the estimated RSR previously described.

To evaluate the contribution of both local $(\alpha)$ and $\beta$ diversity to regional $(\gamma)$ richness (see Gering \& Crist, 2002) the additive forms of $\beta$ and $\alpha$-diversity (= LSR) were plotted against $\gamma$-diversity. When the type I model applies to the data both $\alpha$ and the additive form of $\beta$-diversity will increase proportionally with $\gamma$-diversity (fig. 2a), but when local saturation (type II model) applies to the data, $\alpha$ diversity stays constant when $\gamma$-diversity increases, and consequently $\beta$-diversity has to increase (fig. 2b) (see Loreau, 2000).

\section{Vegetation variables and RSR to predict LSR}

When the regional number of species is zero, the local number of species must also be zero and, therefore, in some
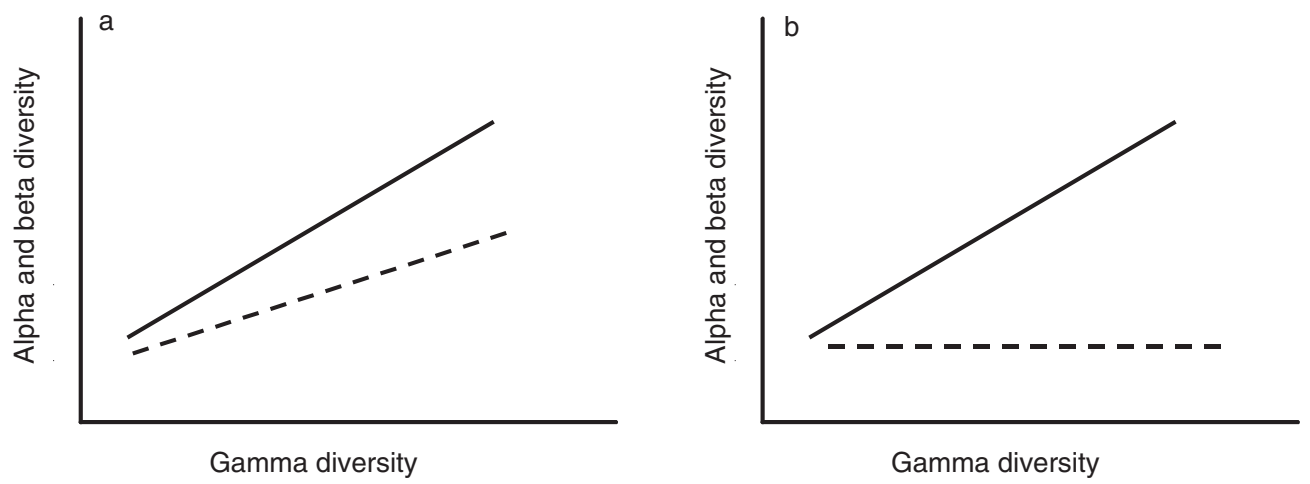

Fig. 2. Relationship between both alpha (- - -) and beta (-) diversities and gamma diversity. (a) When type I model - 'proportional sampling' applies to data both alpha and the additive form of beta-diversity will increase proportionally with gamma diversity; (b) when type II model - 'local saturation' applies to data alpha-diversity stays constant when gamma diversity increases and consequently beta-diversity has to increase (see also Loreau, 2000). 
empirical studies relating LSR to RSR the fitted lines are obtained by a conservative test of linearity forcing the regression line through the origin. However, there are pitfalls in doing this (see Griffiths, 1999; Srivastava, 1999). In the present case, the relevance of the intercept is treated in the modelling process (see below). Most tests of local-regional relationships are based on the standard linear least-squares (OLS) regression of both untransformed and double (log-log) transformed variables. However, data are hierarchical, with pastures nested within habitats (seminatural vs. sown) and habitats nested within islands. Therefore, both habitat and island are grouping factors that could be included in the model as dummy variables coded in a binary fashion, 1 or 0 . One dummy variable is needed for each of the categories except one, since the last is predictable from the others (Zar, 1996). Since our data comprise three islands and two habitats, two dummy variables are needed for island type $\left(D_{1}-\right.$ pastures from Santa Maria (1) vs. other pastures (0); $\mathrm{D}_{2}$ - pastures from Terceira (1) vs. other pastures (0)) and one dummy variable for habitat type $\left(\mathrm{D}_{3}-\right.$ semi-natural (1) vs. sown (0)). These variables can be used to obtain group differences in a hierarchical linear model (see Gering \& Crist, 2002). Therefore, the ability of local vegetation variables and RSR to predict LSR is tested using a hierarchical linear model. By integrating 'effects' of all variables in a particular model, the relative strength of local and regional factors on local species richness was assessed. A multiple regression with dummy variables was used, since a hierarchical method is adequate when there is the need to remove the effect of one or more predictor variables (island and habitat effect) on the dependent variable (Myers, 1990; Drapper \& Smith, 1998). If there is a particular hypothesis to test, such as that one variable of interest will be predictive over and above the standard set of predictors, then the standard explanatory variables set should be entered first in the model, and afterwards the critical variable(s) to see if they contribute significantly to the final model (the hierarchical method) (see Myers, 1990). Thus, first a multiple regression was performed with the empirical explanatory (= independent) variables and later the dummy variables entered one by one in the final model (forward selection):

$$
\mathrm{y}=\mathrm{a}+\mathrm{b}_{1} \cdot x_{1}+\mathrm{b}_{2} \cdot x_{2}+\ldots \ldots+\mathrm{b}_{\mathrm{i}} \cdot x_{\mathrm{i}}+\mathrm{e}+\mathrm{c} \mathrm{D}_{1}+\mathrm{d} \mathrm{D}_{2}+\mathrm{e} \mathrm{D}_{3^{\prime}}
$$

If, for instance, variable $D_{1}$ and $D_{2}$ contribute significantly to the model then:

$$
\begin{aligned}
& y_{1}=(a+c)+b_{i} \cdot x_{i} \\
& y_{2}=(a+d)+b_{i} \cdot x_{i} \\
& y_{3}=a+b_{i} \cdot x_{i}
\end{aligned}
$$

Because the sample size was relatively small $(N=12$ sites) and the number of explanatory variables in the multiple regression models was large (10 empirical variables), data were examined for multicollinearity. A correlation analysis of all explanatory variables was performed looking for covariation and to indicate which variables might generate multicollinearity in multiple regression models. Some predictor variables were largely correlated with one another and the less significant variables, as indicated by simple regressions between LSR and each explanatory variable, were not included in the maximal model at this stage. Multiple regressions were performed using EXCEL (validated by SPSS) to obtain the minimal adequate model explaining the greatest variation in
LSR of the two invertebrate groups. Model simplification was achieved by deleting non-significant terms from the model, until none could be removed without causing an increase in deviance with $P<0.05$. The intercept was also removed in the end, looking for the necessity for its inclusion in the final model. Transformation (logarithmic or square root) of the response and explanatory variables was used where necessary to improve normality of errors. Normality of variables was checked using Q-Q plots and Blom's proportional estimation formula (Kotz et al., 1988) and evaluating residual plots in SPSS.

\section{Results \\ General community patterns}

The suction samples for two summers totalled 29,194 and 3249 specimens of 55 species of sucking insect and 25 species of spider, respectively. The number of singletons totalled four species of spider (15\%) and 13 species of sucking insects (24\%). Doubletons added four species to spiders and three species to the sucking insect assemblages. Among the spiders, 13 species $(52 \%)$ were common (occurring in at least $25 \%$ of the 2 years $\times 12$ regional samples), whereas among the sucking insects, 15 species (27\%) were common. For sucking insects, the most common species accounted for $98 \%$ of the overall abundance and belonged mainly to the families Thripidae (Thysanoptera), Delphacidae, Cicadellidae and Aphididae (Hemiptera). In spiders, there was a clear dominance of the Linyphiidae, with common linyphiid species comprising $99 \%$ of total abundance.

\section{LSR-RSR relationship: contributions of $\alpha$ and $\beta$-diversities}

In spiders, there was no correlation of between years values of $\operatorname{RSR}\left(r_{\mathrm{s}}=0.55 ; P=0.06\right)$ and $\operatorname{LSR}\left(\mathrm{r}_{\mathrm{s}}=0.12 ; P=0.72\right)$ in the 12 pastures, while in sucking insects there was a significant correlation of both variables (RSR: $\mathrm{r}_{\mathrm{s}}=0.67 ; P=$ 0.01 ; LSR: $r_{s}=0.66 ; P=0.02$ ). The plots relating LSR with RSR indicated a type II model (ceiling effect) for spiders (fig. 3a,c) and a type I model (proportional sampling) for sucking insects (fig. $3 b, d$ ). The contribution of $\beta$-diversity to $\gamma$-diversity (regional richness) far outweighs the contribution of $\alpha$-diversity in spider assemblages (fig. $4 \mathrm{a}, \mathrm{c}$ ). Thus, there was no evidence of proportional sampling between local and regional species richness in either year, which agrees with the type II model (fig. 2b). In sucking insects, there was a tendency for $\beta$-diversity to increase in importance in richer regions, particularly in year 2 (fig. $4 \mathrm{~d}$ ). However, $\alpha$-diversity was correlated positively with $\gamma$-diversity (fig. $4 b, d$ ), which agrees with the type I model (fig. 2a).

\section{Vegetation variables and RSR to predict LSR}

The local species richness (LSR) of spiders was significantly positively correlated with the cover abundance of grasses (PEGca), the total number of forb species ( $\mathrm{tFspp}$ ) and RSR (plus quadratic term) in the summer of year 1 and with the total number of grass species (tGspp) and perennial grass height (PEG-ht) in the summer of year 2 (table 1a). The intercept was only needed in the final model in year 1 . The dummy variables did not contribute significantly to the final models. The LSR of sucking insects was consistently and significantly positively correlated only with the RSR for both sampling occasions (table 1b). The intercept was not needed 

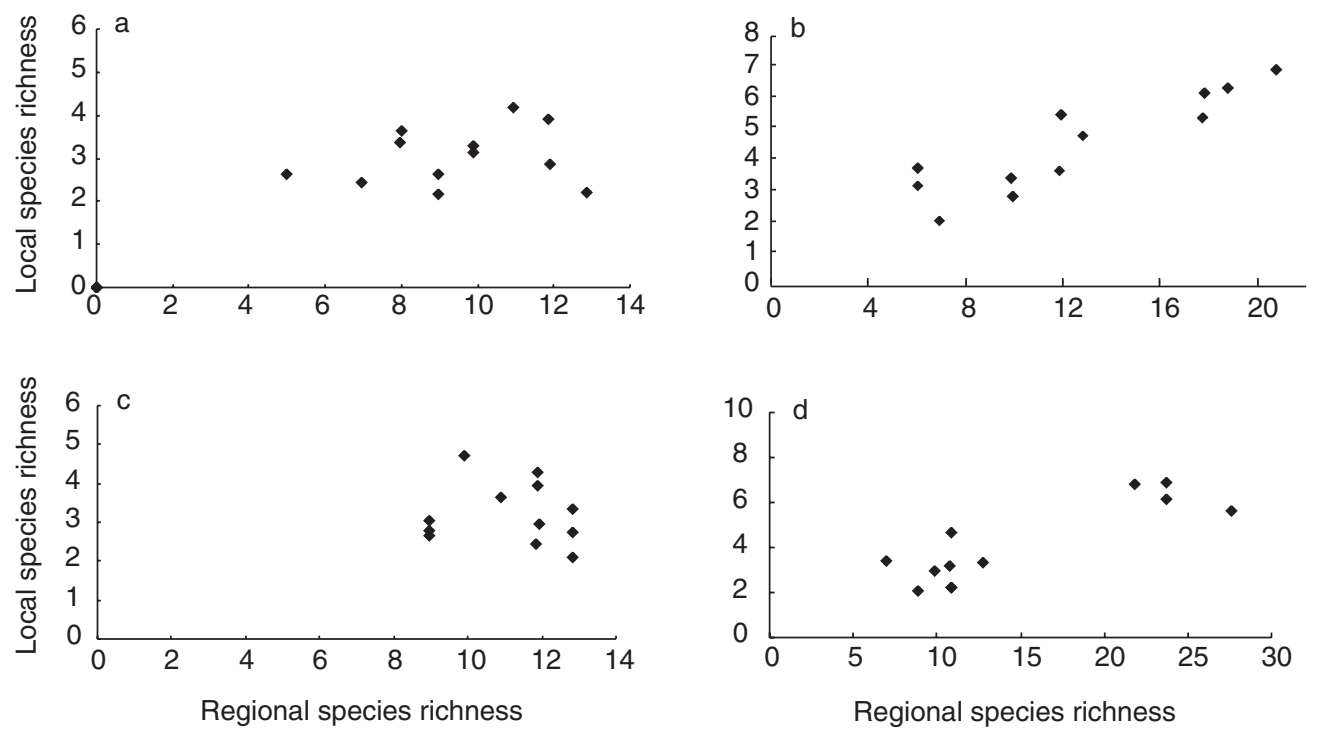

Fig. 3. Plotting local species richness against regional species richness for spiders (a, c) and sucking insect herbivores (b, d), in year 1 (a, b) and year 2 (c, d) in Azorean pastures.

Table 1. Predicting local species richness (LSR) of spiders (a) and sucking insects (b) in pastures on the Azores; analysis of deviance (ANODEV) table for hierarchical multiple regression with step-wise omission of non-significant terms, beginning from the maximal model.

\begin{tabular}{lcrc}
\hline Explanatory variable & Deviance & F & Significance \\
\hline (a) Spiders & & & \\
Summer 1994 & & & \\
Intercept & 0.0312 & 7.72 & $P<0.05$ \\
log tFspp & 0.0409 & 10.13 & $P<0.05$ \\
sqrt PEGca & 0.0407 & 10.09 & $P<0.05$ \\
RSR & 0.0245 & 6.07 & $P<0.05$ \\
RSR & 0.0226 & 5.60 & $P<0.05$ \\
sqrt PEGca ${ }^{2}$ & 0.0016 & 0.37 & n.s. \\
W-a & 0.0012 & 0.24 & n.s. \\
sqrt PEFca & 0.0014 & 0.23 & n.s. \\
Dummy Var. 1 (S. Maria) & 0.0064 & 1.77 & n.s. \\
Dummy Var. 3 (Habitat) & 0.0014 & 0.32 & n.s. \\
Dummy Var. 2 (Terceira) & 0.0003 & 0.07 & n.s.
\end{tabular}

$\log \mathrm{LSR}=-1.16( \pm 0.41)+0.54( \pm 0.17) \log \mathrm{tFspp}+0.0033$

$( \pm 0.00107)$ sqrt PEGca $+0.17( \pm 0.07)$ RSR $-0.0087( \pm 0.0037)$

$\mathrm{RSR}^{2} ; P=0.043 ; \mathrm{r}^{2}=0.71$

$\begin{array}{llrc}\text { Summer 1995 } & & & \\ \text { Intercept } & 0.074 & 0.59 & \text { n.s. } \\ \text { tGspp } & 1.383 & 11.17 & P<0.01 \\ \text { PEG-ht } & 1.079 & 8.72 & P<0.05 \\ \text { sqrt (PEFca) } & 0.071 & 0.55 & \text { n.s. } \\ \text { RSR }_{2} & 0.123 & 0.94 & \text { n.s. } \\ \text { RSR } & 0.019 & 0.13 & \text { n.s. } \\ \text { Dummy Var. 1 (S. Maria) } & 0.182 & 1.47 & \text { n.s. } \\ \text { Dummy Var. 2 (Terceira) } & 0.09 & 0.72 & \text { n.s. } \\ \text { Dummy Var. 3 (Habitat) } & 0.06 & 0.43 & \text { n.s. }\end{array}$

LSR $=0.15( \pm 0.04) \mathrm{tGspp}+0.198( \pm 0.04)$ PEG-ht; $P=0.00026 ; \mathrm{r}^{2}=0.82$

$\begin{array}{lrrc}\text { Summer 1995 } & & & \\ \text { Intercept } & 1.59 & 1.70 & \text { n.s. } \\ \text { RSR } & 12.16 & 13.38 & P<0.01 \\ \text { V-ht } & 1.17 & 1.28 & \text { n.s. } \\ \text { sqrt (PEFca) } & 0.56 & 0.59 & \text { n.s. } \\ \text { tGspp } & 0.16 & 0.15 & \text { n.s. } \\ & & & \\ \text { Dummy Var. 2 (Terceira) } & 3.63 & 4.98 & P=0.05 \\ \text { Dummy Var. 1 (S. Maria) } & 1.07 & 1.54 & \text { n.s. } \\ \text { Dummy Var. 3 (Habitat) } & 0.04 & 0.05 & \text { n.s. }\end{array}$

(b) Sucking insects

$\begin{array}{lccc}\text { Summer 1994 } & & & \\ \text { Intercept } & 0.0070 & 0.73 & \text { n.s. } \\ \text { log RSR } & 0.0863 & 10.0 & P<0.05 \\ \text { sqrt PEGca } & 0.0187 & 2.17 & \text { n.s. } \\ \text { V-ht } & 0.0113 & 1.37 & \text { n.s. } \\ \text { log tFspp } & 0.0068 & 0.80 & \text { n.s. } \\ \text { sqrt PEFca } & 0.0095 & 1.15 & \text { n.s. } \\ \text { W- } \alpha & 0.0042 & 0.46 & \text { n.s. } \\ & & & \\ \text { Dummy Var. 1 (S. Maria) } & 0.0115 & 1.25 & \text { n.s. } \\ \text { Dummy Var. 2 (Terceira) } & 0.0032 & 0.32 & \text { n.s. } \\ \text { Dummy Var. 3 (Habitat) } & 0.0031 & 0.31 & \text { n.s. }\end{array}$

$\log \mathrm{LSR}=0.59( \pm 0.03) \log \mathrm{RSR} ; P<0.0001 ; \mathrm{r}^{2}=0.66$

$\mathrm{LSR}=0.26( \pm 0.016) \mathrm{RSR}+1.02( \pm 0.46) \mathrm{D} 2 ; P=0.0005 ; \mathrm{r}^{2}=0.80$

Dummy variables in italics entered in the minimal adequate model in a second stage using forward selection (see text for explanation). For each analysis the minimal adequate model (parameters \pm 1 SE), the significance and the $\mathrm{r}^{2}$ are shown. RSR, Regional species richness; PEFca, perennial forb cover abundance; PEGca, perennial grass cover abundance;V-ht, weighted mean height of all plant species; PEG-ht, weighted mean height of the perennial grasses; $\mathrm{W}-\mathrm{a}$, total vegetation William's alpha diversity; $\mathrm{tFspp}$, total forb species; tGspp, total grass species.

Dummy Var. 1, 2, and 3 are k-1 dummy variables for $\mathrm{k}$ different islands or habitats in the study. 
in the final models. Only in the second year, one dummy variable entered the final model, the Terceira island effect $\left(\mathrm{D}_{2}\right)$ (table $\left.1 \mathrm{~b}\right)$.

\section{Discussion}

This study was conducted over two years, using the same comprehensive sampling protocol, allowing a comparison between years, in the LSR-RSR relationship. Data for spiders were consistent with the predictions of the saturation model (type II model) while data from sucking insects were consistent with the predictions of the proportional sampling model (type I model). The results showed consistent patterns between years but also some slight differences, which allow a more realistic interpretation of the relative importance of local and regional processes.

The correct estimation of local and regional species richness has been considered critical for determining the shape of the relationship between local and regional species richness (Srivastava, 1999). In this study, the sampling method was uniform in all quadrats within each region (pasture). Further, the pastures (regions) can be considered a homogeneous habitat, thereby avoiding the occurrence of several habitat specialists in a particular plot (local), which may create spurious asymptotes as a result of overestimation of regional richness through the inclusion of plot specialists (i.e. 'restricted singletons'). The data analysed here include an even higher percentage of singleton and doubleton species in the non-saturated assemblage (sucking-insects) than in the saturated community (spiders), and consequently the 'ceiling' effect obtained for spiders (fig. 3a,c) could not be explained by overestimation of RSR. However, rare and vagrant species are also likely to have a role in the communities (Gaston, 1994).

Despite some recent evidence to the contrary (see Chown, 1992; Denno et al., 1995; Stewart, 1996; McGeoch \& Chown, 1997; Moon \& Stilling, 2002), it was predicted that assemblages of herbivorous arthropods are not structured by competition (see Strong et al., 1984). The proportional increase of LSR with RSR, documented on several scales and for many taxa (see revision in Cornell \& Karlson, 1997; Srivastava, 1999), also emerges in our fine-scale study of pasture sucking herbivores. Multicollinearity among the set of predictor variables was minimal, which strengthens the interpretation that RSR was the only important predictor variable of LSR in sucking insects. In one of the final models (see table $1 b$ ), a different scale of regional richness was also retained, which shows that a broad range of regional scales may influence local processes (see Huston, 1999). Competition may be more likely to occur between closely related taxa, because of the similarity in feeding niches (Denno et al., 1995). The functional group of sucking insects studied here comprises very different taxonomic and ecological taxa, with different dynamics and feeding behaviours (sap-feeders both above and below ground) and host-plant preferences (both grass and forb-feeders). This may explain the small impact of interspecific interactions as shown in figs $3 b$,d and $4 b$,d. Most of the experimental work already performed with assemblages of herbivores also supports the 'proportional sampling hypothesis' (Opler, 1974; Cornell, 1985a,b; Hawkins \& Compton, 1992; Lawton et al., 1993; Westoby, 1993). Therefore, it is suggested that the available pool of species (RSR) mainly dictates the species richness patterns of sucking herbivores at the local finescale. The biological mechanisms that allow a regional enrichment of sucking insects at the local fine-scale need further investigation. Total abundance of sucking insects increased with LSR (year 1: $\log$ (abund.) $=0.6181+1.437 \log$ LSR, $\mathrm{r}^{2}=0.74, P=0.0003$; year 2 : $\log$ (abund.) $=0.94+0.87$ $\log$ LSR, $\mathrm{r}^{2}=0.43, P=0.02$ ) and consequently there was a similar probabilistic recruitment between species and no resource limitation. No such relationship between abundance and LSR occured in the spider assemblage.

In the spiders, plot richness (LSR) was found to be independent of pasture richness (RSR) and well explained by fine-scale vegetation diversity and structure. In fact, RSR was only retained in one of the models (year 1 ; 1994) and accounted for less of the explained variation in LSR than did vegetation structure. Moreover, none of the higher rank regional variables were retained in the final hierarchical models. Other evidence showed that there was an increase of $\beta$-diversity with $\gamma$-diversity and no-increase of $\alpha$-diversity with $\gamma$-diversity (fig. $4 a, c$ ), which is suggestive of niche packing and strong species interactions at the local finescale. Although some pastures were richer in species, the average number of species per plot was small, with the largest part of RSR being explained by $\beta$-diversity. The ecological interpretation of $\beta$-diversity is not straightforward. It might be expected that $\beta$-diversity should increase with pasture heterogeneity. In fact, more structurally complex pastures harbour more spider species per plot (see table 1a), probably due to more niches being available.

Earlier evidence of saturation in animal assemblages was reported for island birds in the Caribbean (Terborgh \& Faaborgh, 1980) and fish assemblages in lakes (Tonn et al., 1990), but these were later refuted (Cornell, 1993). Cornell \& Lawton (1992) and Cornell (1993) stated that if a ceiling is found, additional observations and/or experiments should be performed to discern true saturation from stochastic equilibrium or pool exhaustion. Recently, Soares et al. (2001) showed that there is a pattern of saturation in LSR of ant communities in tropical forest litter, but concluded that species saturation in ground-dwelling ant communities was produced by habitat specialization and/or by stochastic equilibrium and not by interactive processes. Winkler \& Kampichler (2000) also found saturation at a local scale in grassland Collembola suggesting that the pattern could be explained by local interactions. Both these studies (Winkler \& Kampichler, 2000; Soares et al., 2001) were performed at scales similar to this study and found saturation patterns, which could indicate pseudo-saturation due to a fine-scale effect (see Loreau, 2000). However, sucking insects showed a non-saturating LSR-RSR pattern at the same scale and Gering \& Crist (2002) also obtained a type I model in a finescale study of a canopy beetle assemblage. Indeed, there is a considerable advantage in the fine-scale used in this study, since the probability of species interactions is higher and the interpretation of patterns more easily related to processes operating at the local scale, such as vegetation heterogeneity and diversity (see also Collins et al., 2002).

The data do not support the pool exhaustion explanation for the observed 'ceiling pattern' in spiders. The regional pool was assessed directly from species composition of the local assemblages, and thus, the inclusion of non-pasture dwellers was avoided and RSR not overestimated. The stochastic equilibrium explanation implies that there is a balance between local colonization and extinction rates, which is independent of interspecific relationships (Cornell \& Lawton, 1992). Frequent extinctions at the local scale, 

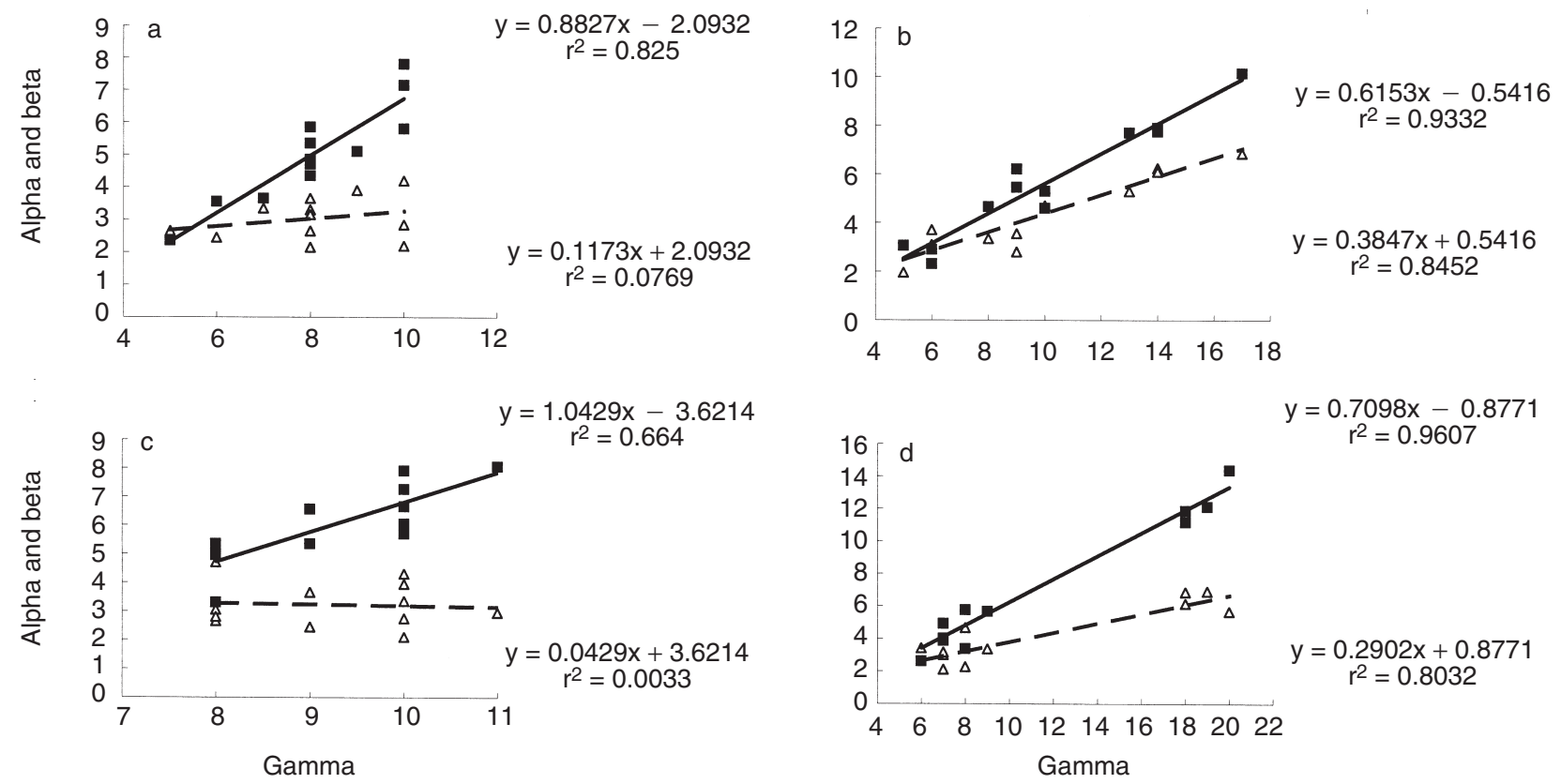

Fig. 4. Relationship between alpha $(\triangle)$ or beta ( $\square)$ diversity and gamma diversity for spiders $(a, c)$ and sucking insect herbivores (b, d), in year $1(\mathrm{a}, \mathrm{b})$ and year $2(\mathrm{c}, \mathrm{d})$ in Azorean pastures. The linear statistics are presented to compare the slopes of the alpha-gamma (- -) and beta-gamma $(-)$ relationships.

balanced by constant immigration rates, could be expected in the spider assemblage due to their high mobility. However, the high frequency and density of some spider species does not support extinction at the local scale and the high $\beta$-diversity suggests eventual extinction of rare, less competitive species, at the local scale. In addition, there is an increase in mean plot species occurrence (MPSO) with increasing LSR (year 1: $\log$ MPSO $=0.32+1.09 \log \mathrm{LSR}, \mathrm{r}^{2}=$ $0.44, P=0.017$; Year 2: MPSO $=-0.2939+2.28239$ LSR, $\mathrm{r}^{2}=$ $0.82, P<0.0001$ ) (see fig. 5), which does not suggest local extinction but rather within-pasture spatial spread of common dominating species. In sucking insects, there is no such correlation in either year.

Natural experiments have shown clear evidence of the impact of interspecific competition over short time scales in web-building spiders (Wise, 1995). Spiders might also be expected to have relatively predictable assemblages based on habitat structure (Brown, 1991b; Uetz, 1991; Gibson et al., 1992; Borges \& Brown, 2001). If competition is occurring in the spiders (mainly web-building spiders), different features of the assemblages could be explained by the architecture of the vegetation of the habitats studied (Brown, 1991b; Uetz, 1991), leading to some niche assortment between species. Borges \& Brown (2001) showed that two measures of vegetation structure ('perennial grass cover abundance' and total vegetation 'Williams's $\alpha$ diversity') were positively correlated with the abundance of web-building spiders. Moreover, as shown here, some vegetation variables also explain LSR. Consequently, the non-linear relationship obtained between LSR and RSR might reflect some sort of niche saturation within the spider assemblage at the plot scale, as a consequence of strong interspecific interactions.

Grazing management also affects the community structure of spider assemblages (Gibson et al., 1992), and so disturbance effects of grazing may explain the saturation patterns obtained in the spider assemblage. It could be hypothesized that, after a grazing event, higher extinction rates depressed the populations and that the regularity of grazing events in the Azorean pastures did not allow populations to recover through immigration from the surrounding landscape. However, this seems unlikely, since pastures are grazed in rotation and therefore provide a mosaic of vegetation structures. Thus, source populations were potentially available for recolonization ('mass effects' sensu Shmida \& Wilson, 1985). Moreover, most of the webbuilding spiders were linyphiid spiders, engaged in aerial dispersal by 'ballooning' (Wise, 1995). Because of their high dispersal ability, local spider extinctions are likely to be rare (Halley et al., 1996). Results also showed that there was some within-pasture range increase in locally richer pastures (fig. 5). The explanation of saturation found in the spiders may be related to competition between species within the dominant family (Linyphiidae), which have similar spatial and ecological requirements. Such species include Tenuiphantes tenuis (Blackwall), Erigone atra (Blackwall) and Oedothorax fuscus (Blackwall). Moreover, no relationship was found between spider abundance and LSR in either year, which implies niche limitation.

In summary, the results confirm the predictions of recent empirical studies suggesting that species assemblages are random samples drawn from a pool of potential colonists, and also that spider communities may be largely structured by interspecific competition or local features of the habitat (Wise, 1995). Spider assemblages, in a particular small patch, probably represent a collection of individuals of the species present, under the constraints of habitat structure and limited niche space. Pasture management may also have profound effects on local spider assemblages, since local 

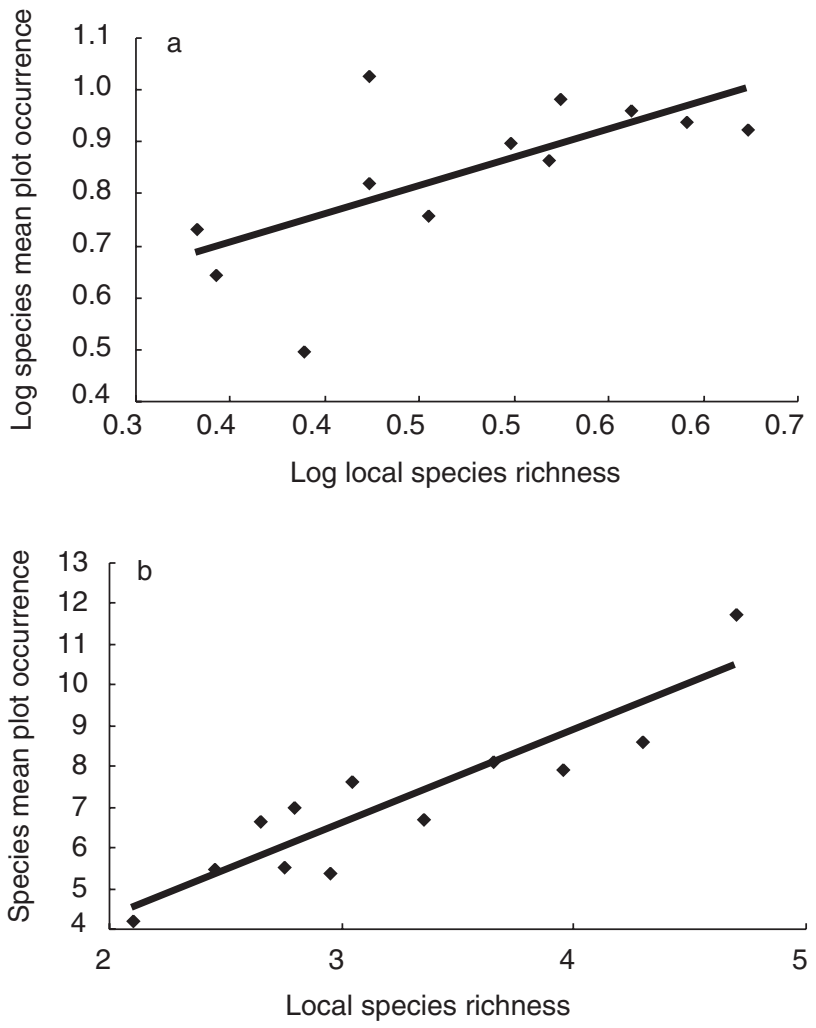

Fig. 5. Relationship between species mean plot occurrences and local species richness for spiders in year 1 (a) and year 2 (b) in Azorean pastures. In (a) variables were transformed to improve normality. See text for further explanations.

spider richness seems to be related to well-developed and complex vegetation.

It is also important to consider the potential utility of $\alpha, \beta$ and $\gamma$ measures of species richness in pasture management and conservation-management of semi-natural grasslands. If saturation occurs at the local scale, then $\gamma$-diversity could be of limited value in identifying levels of mean species richness at the local scale. An investment in standardized sampling within regions, to obtain measures of $\alpha$ and $\beta$ diversity, would greatly enhance the understanding of processes operating at local and regional scales.

\section{Acknowledgements}

This paper greatly benefited from the revisions of two anonymous referees. We are also grateful to G. Masters for the adaptation of computer software to analyse pointquadrat data. This research was funded by JNICT (Junta Nacional de Investigação Científica e Tecnológica, Lisboa, Portugal) and the Azorean Agriculture Services (Secretaria Regional da Agricultura e Pescas).

\section{References}

Borges, P.A.V. (1997) Pasture arthropod community structure in Azorean islands of different geological age. $245 \mathrm{pp}$. PhD thesis, Imperial College, University of London.
Borges, P.A.V. (1999a) A list of arthropod species of sown and semi-natural pastures of three Azorean islands (S. Maria, Terceira and Pico) with some conservation remarks. Açoreana 9, 13-34.

Borges, P.A.V. (1999b) Plant and arthropod species composition of sown and semi-natural pasture communities of three Azorean islands (S. Maria, Terceira and Pico) Arquipélago 17, 1-21.

Borges, P.A.V. \& Brown, V.K. (1999) Effect of island geological age on the arthropod species richness of Azorean pastures. Biological Journal of the Linnean Society 66, 373-410.

Borges, P.A.V. \& Brown, V.K. (2001) Phytophagous insects and web-building spiders in relation to pasture vegetation complexity. Ecography 24, 68-82.

Brown, V.K. (1991a) The importance of habitat structure in the maintenance of insect species diversity. pp.49-55 in Pineda, F.D., Casado, M.A., Miguel, J.M. de \& Montalvo, J. (Eds) Biological diversity. Madrid, Fundación Ramón Areces.

Brown, V.K. (1991b) The effects of changes in habitat structure during succession in terrestrial communities. pp. 141-168 in Bell, S.S., McCoy, E.D. \& Mushinsky, H.R. (Eds) Habitat structure: the physical arrangement of objects in space. New York, Chapman and Hall.

Brown, V.K. \& Gange, A.C. (1989) Insect herbivory during early plant succession. Oikos 54, 67-76.

Brown, V.K., Jepsen, M. \& Gibson, C.W.D. (1988) Insect herbivory: effects on early old field succession demonstrated by chemical exclusion methods. Oikos 52, 293-302.

Caley, M.J. \& Schluter, D. (1997) The relationship between local and regional diversity. Ecology 78, 70-80.

Chown, S.L. (1992) A preliminary analysis of weevil assemblages in the sub-Antarctic: local and regional patterns. Journal of Biogeography 19, 87-98.

Collins, S.L., Glenn, S.M. \& Briggs, J.M. (2002) Effect of local and regional processes on plant species richness in tallgrass prairie. Oikos 99, 571-579.

Colwell, R.K. (1997) EstimateS, statistical estimation of species richness and shared species from samples. Version 6. User's guide and application published at http://viceroy.eeb. uconn.edu/estimates.

Colwell, R.K. \& Coddington, J.A. (1995) Estimating terrestrial biodiversity through extrapolation. pp. 101-118 in Hawksworth, D.L. (Ed.) Biodiversity, measurement and estimation. London, Chapman \& Hall.

Cornell, H.V. (1985a) Local and regional richness of cynipine gall wasps on California oaks. Ecology 66, 1247-1260.

Cornell, H.V. (1985b) Species assemblages of cynipid gall wasps are not saturated. American Naturalist 126, 565-569.

Cornell, H.V. (1993) Unsaturated patterns in species assemblages: the role of regional processes in setting local species richness. pp. 243-252 in Ricklefs, R.E. \& Schluter, D. (Eds) Species diversity in ecological communities. Historical and geographical perspectives. Chicago and London, The University of Chicago Press.

Cornell, H.V. \& Karlson, R.H. (1997) Local and regional processes as controls of species richness. pp. 250-270 in Tilman, D. \& Kareiva, P. (Eds) Spatial ecology - the role of space in population dynamics and interspecific interactions. New Jersey, Princeton University Press.

Cornell, H.V. \& Lawton, J. (1992) Species interactions, local and regional processes, and limits to the richness of ecological communities: a theoretical perspective. Journal of Animal Ecology 61, 1-12. 
Dawah, H.A., Hawkins, B.A. \& Claridge, M.F. (1995) Structure of the parasitoid communities of grass-feeding chalcid wasps. Journal of Animal Ecology 64, 708-720.

Denno, R.F., McClure, M.S. \& Ott, J.R. (1995) Interspecific interactions in phytophagous insects: competition reexamined and resurrected. Annual Review of Entomology 40, 297-331.

Drapper, N. \& Smith, H. (1998) Applied regression analysis. 407 pp. 3rd edn. New York, John Wiley \& Sons.

Fox, J.W., McGrady-Steed, J. \& Petchey, O.L. (2000) Testing for local species saturation with nonindependent regional species pools. Ecology Letters 3, 198-206.

Garcia, V. \& Furtado, M. (1991) Desenvolvimento agrícola dos ecossistemas insulares açoreanos. pp. 5-8 in Dias, E., Carretas, J.P. \& Cordeiro, P. (Eds) Primeiras Jornadas Atlânticas de Protecção do Meio Ambiente - Açores, Madeira, Canárias e Cabo Verde. Secretaria Regional do Turismo e Ambiente, Angra do Heroísmo.

Gaston, K.J. (1994) Rarity. 205 pp. London, Chapman \& Hall.

Gaston, K.J. \& Blackburn, T.M. (2000) Pattern and process in macroecology. 348 pp. Oxford, Blackwell Science.

Gering, J.C. \& Crist, T. (2002) The alpha-beta-regional relationship: providing new insights into local-regional patterns of species richness and scale dependence of diversity components. Ecology Letters 5, 433-444.

Gibson, C.W.D., Dawkins, H.C., Brown, V.K. \& Jepsen, M. (1987) Spring grazing by sheep: effects on seasonal change during early old field succession. Vegetatio 70, 33-43.

Gibson, C.W.D., Hambler, C. \& Brown, V.K. (1992) Changes in spider (Araneae) assemblages in relation to succession and grazing management. Journal of Applied Ecology 29, 133-142.

Griffiths, D. (1999) On investigating local-regional species richness relationships. Journal of Animal Ecology 68, 1051-1055.

Halley, J.M., Thomas, C.F.G. \& Jepson, P.C. (1996) A model for the spatial dynamics of linyphiid spiders in farmland. Journal of Applied Ecology 33, 471-492.

Hawkins, B.A. \& Compton, S.G. (1992) African fig wasp communities: vacant niches and latitudinal gradients in species richness. Journal of Animal Ecology 61, 361-372.

Henderson, P.A. \& Seaby R.M.H. (1998) Species diversity and richness - Projecto Mamiraua, Version 2.3. Lymington, UK. Pisces Conservation Ltd. (www.irchouse.demon.co.uk).

Hugueny, B. \& Paugy, D. (1995) Unsaturated fish communities in African rivers. American Naturalist 146, 162-169.

Huston, M.A. (1999) Local processes and regional patterns: appropriate scales for understanding variation in the diversity of plants and animals. Oikos 86, 393-401.

Kotz, S., Johnson, N.L. \& Read, C.B. (Eds) (1988) Encyclopedia of statistical sciences. Vol 1. 496 pp. New York, John Wiley \& Sons, Inc.

Lawton, J.H. (1999) Are there general laws in ecology? Oikos 84,177-192.

Lawton, J.H., Lewinsohn, T.M. \& Compton, S.G. (1993) Patterns of diversity for the insect herbivores on bracken. pp. 178-184 in Ricklefs, R.E. \& Schluter, D. (Eds) Species diversity in ecological communities. Historical and geographical perspectives. Chicago and London, The University of Chicago Press.

Loreau, M. (2000) Are communities saturated? On the relationship between $\alpha, \beta$, and $\gamma$ diversity. Ecology Letters 3, 73-76.

Martins, A.M.F. (1993) The Azores - westernmost Europe: where evolution can be caught red-handed. Boletim do Museu Municipal do Funchal, Sup. 2, 181-198.
McGeoch, M.L. \& Chown, S.L. (1997) Evidence of competition in a herbivorous, gall-inhabiting moth (Lepidoptera) community. Oikos 78, 107-115.

Moon, D.C. \& Stilling, P. (2002) Top-down, bottom-up, or side to side? Within-trophic-level interactions modify trophic dynamics of a salt marsh herbivore. Oikos 98, 480-490.

Myers, R.H. (1990) Classical and modern regression with applications. 480 pp. 2nd edn. Belmont, California, Duxbury Press.

Opler, P.A. (1974) Oaks as evolutionary islands for leaf-mining insects. American Scientist 62, 67-73.

Ricklefs, R.E. (1987) Community diversity: relative roles of local and regional processes. Science 235, 167-171.

Ricklefs, R.E. \& Schluter, D. (Eds) (1993) Species diversity in ecological communities. Historical and geographical perspectives. 414 pp. Chicago and London, The University of Chicago Press.

Shmida, A. \& Wilson, M.V. (1985) Biological determinants of species diversity. Journal of Biogeography 12, 1-20.

Soares, S.M., Schoereder, J.H \& DeSouza, O.G. (2001) Processes involved in species saturation of grounddwelling ant communities (Hymenoptera, Formicidae). Austral Ecology 26, 1-6.

Southwood, T.R.E. (1978) Ecological Methods. 524 pp. 2nd edn. London, Chapman \& Hall.

Southwood, T.R.E. \& Henderson, P.A. (2000) Ecological methods. 575 pp. 3rd edn. London, Blackwell Science.

Srivastava, D.S. (1999) Using local-regional richness plots to test for species saturation: pitfalls and potentials. Journal of Animal Ecology 68, 1-16.

Stewart, J.A. (1996) Interspecific competition reinstated as an important force structuring insect herbivore communities. Trends in Ecology and Evolution 11, 233-234.

Strong, D.R, Lawton, J.H. \& Southwood, T.R.E. (1984) Insects on plants. Community patterns and mechanisms. 293 pp. Oxford, Blackwell Scientific Publications.

Terborgh, J.W. \& Faaborgh, J. (1980) Saturation of bird communities in the West Indies. American Naturalist 116, 178-195.

Tonn, W., Magnuson, J.J., Rask, M. \& Toivonen, J. (1990) Intercontinental comparison of small-lake fish assemblages: the balance between local and regional processes. American Naturalist 136, 345-375.

Uetz, G.W. (1991) Habitat structure and spider foraging. pp. 325-348 in Bell, S.S., McCoy, E.D. \& Mushinsky, H.R. (Eds) Habitat structure: the physical arrangement of objects in space. New York, Chapman and Hall.

Valkenburgh, B.V. \& Janis, C.M. (1993) Historical diversity patterns in north American large herbivores and carnivores. pp. 330-340 in Ricklefs, R.E. \& Schluter, D. (Eds) Species diversity in ecological communities. Historical and geographical perspectives. Chicago and London, The University of Chicago Press.

Valone, T.J. \& Hoffman, C.D. (2002) Effects of regional pool size on local diversity in small-scale annual plant communities. Ecology Letters 5, 477-480.

Veech, J.A., Summerville, K.S., Crist, T.O. \& Gering, J.C. (2002) The additive partitioning of species diversity: recent revival of an old idea. Oikos, 99 3-9.

Westoby, M. (1993) Biodiversity in Australia compared with other continents. 170-177 in Ricklefs, R.E. \& Schluter, D. (Eds) Species diversity in ecological communities. Historical and geographical perspectives. Chicago and London, The University of Chicago Press. 
Whittaker, R.H. (1972) Evolution and measurement of species diversity. Taxon 21, 213-251.

Whittaker, R.J., Willis, K.J. \& Field, R. (2001) Scale and species richness: towards a general, hierarchical theory of species diversity. Journal of Biogeography 28 453-470.

Winkler, H. \& Kampichler, C. (2000) Local and regional species richness in communities of surface-dwelling grassland Collembola: indication of species saturation. Ecography 23, 385-392.
Wise, D.H. (1995) Spiders in ecological webs. 328 pp. Melbourne, Cambridge University Press.

Zar, J.H. (1996) Biostatistical Analysis. 662 pp. 3rd edn. New Jersey, Prentice-Hall International.

(Accepted 21 December 2003)

(C) CAB International, 2004 


\section{NEW BOOK}

\section{INFORMATION}

\author{
From
}

CABI PUBLISHING

\section{Advances in Stored Product Protection}

Edited by P F Credland, Royal Holloway, University of London, UK, D M Armitage, C H Bell and P M Cogan, Central Science Laboratory, York, UK, and E Highley, Clarus Design, Canberra, Australia

ISBN

July 2003

Hardback

ŁI50.00 (US\$250.00)
0851996914

II 92 pages

A4 format

\section{Readership}

Crop protection, postharvest biology, pest management.

\section{Description}

The International Working Conference on Stored Product Protection, held every four years, is the premier world forum for the presentation of research results and reviews on the safe storage of durable foodstuffs, of which cereal grains, pulses and oilseeds make up the largest components. This book presents the proceedings of the 8th conference, held in York, UK, in July 2002.

This book highlights work on the pests and diseases that may cause spoilage, adverse health effects and loss of the crop after harvest, and discusses new techniques for the safe, effective and environmentally friendly management of stored commodities. With nearly 200 keynote, oral and poster papers and contributions from leading experts from around the world, the contents cover the future of stored product protection and the impacts of global issues, food safety, chemical and physical control, and processing and applications. The volume will interest applied entomologists, plant pathologists, postharvest biologists, and agricultural engineers.

\section{To view full contents or to order online please visit www.cabi-publishing.org/bookshop}

Postage \& Packing: For pre-paid orders in the UK, please add $£ 2.75$ for the Ist book and $60 \mathrm{p}$ for each additional book ordered (up to max. of 10). For prepaid orders elsewhere, please add $£ 4.00$ for the Ist book and $£ 1.00$ for each additional book. For orders not pre-paid, postage and packing will be charged according to the weight of the book.
CABI Publishing, CAB International Wallingford,

Oxfordshire OXI0 8DE, UK

Tel: +44(0) |49| 832। I |

Fax: $+44(0)|49| 829292$

Email: orders@cabi.org
CABI Publishing North America 875 Massachusetts Avenue, 7th Floor Cambridge, MA 02139, USA

Tel: 0016173954056

Fax: 00। 6173546875

Email:cabi-nao@cabi.org 